\title{
Trockeneisreinigung als Dienstleistung
}

\author{
Dass die Trockeneisreinigung für unterschiedlichste Aufgabenstellungen einsetzbar ist, \\ belegt das breite Leistungsspektrum eines Servicedienstleisters.
}

Durch die große Anzahl unterschiedlicher Reinigungsaufgaben und zu reinigender Materialien benötigte Cold Bull Enterprises anpassungsfähige Reinigungssysteme. Darüber hinaus müssen die Geräte transportabel sein, da die Reinigung meist vor Ort erfolgt. „Wir informierten uns zu Beginn über die verschiedenen mobilen Reinigungslösungen und sind mit der Trockeneisreinigung von Cold Jet fündig geworden“, erinnert sich Frank Fuchs, Firmengründer und Geschäftsführer.

\section{Unterschiedliche Geräte}

Für die Aufgaben in der industriellen Reinigung braucht das Unternehmen Lösungen, die Verunreinigungen effektiv ent-

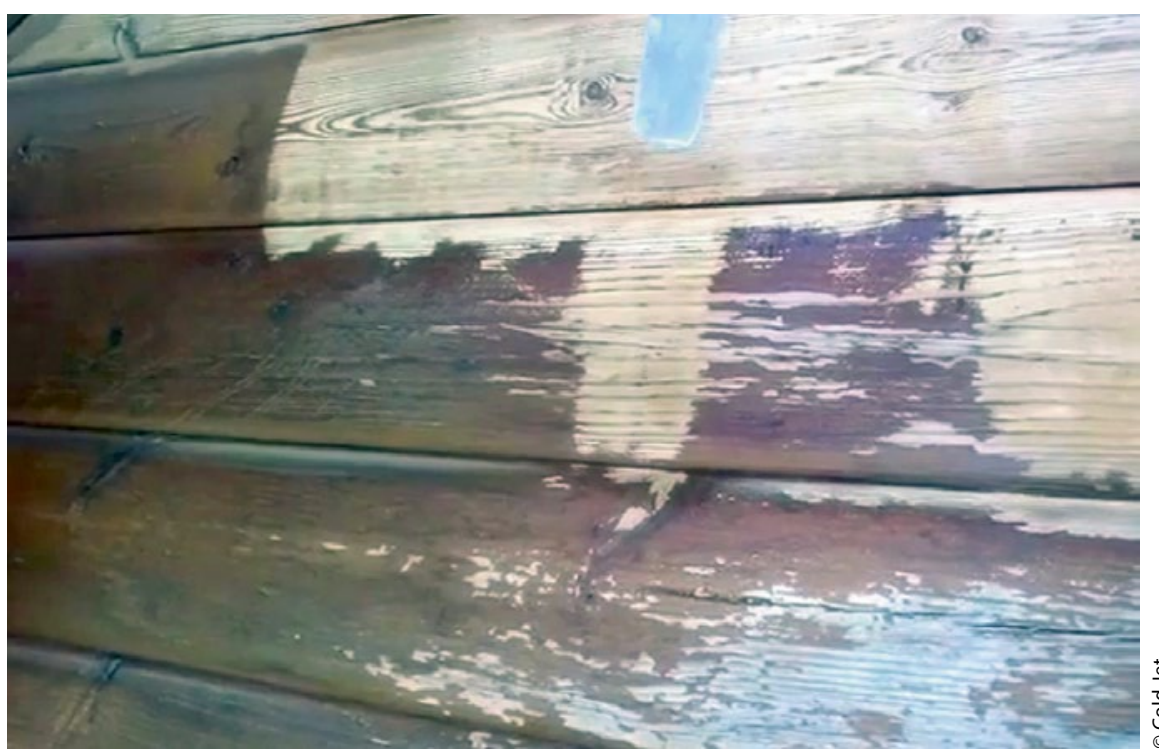

Unterschiedliche Geräte ermöglichen die effektive und schonende Reinigung von Maschinen, Robotern und Produktionsanlagen ebenso wie von empfindlichen Holzflächen. fernen, ohne abrasiv zu sein und für die Mitarbeiter leicht zu bedienen sind. Diese Anforderungen erfüllen die Reinigungsgeräte, mit denen Cold Bull Enterprises inzwischen arbeitet (SDI Select 60, $\mathrm{i}^{3}$ MicroClean und Aero 40 FP). Die Vorgehensweise ist dabei meist so, dass zunächst mit dem MicroClean-Gerät ermittelt wird, ob besser mit feinen, von einem Eisblock abgeschabten, Mikro-Eispartikeln oder mit Trockeneispellets gereinigt wird.

Mit diesen Lösungen kann der Servicedienstleister die gesamte Bandbreite der Reinigungsanwendungen abdecken. Dazu zählt unter anderem die Reinigung von Druckmaschinen, Industrierobotern, Spritzgussformen und Schaltschränken. „Bei diesen Anwendungen kommt es

\section{$\frac{1}{3}$ .}

\section{Cold Bull Enterprises}

Stutensee, Tel. 072447418488

www.cold-bull.de auch darauf an, dass der Produktionsprozess in den Firmen nicht lange unterbrochen wird“, erklärt Frank Fuchs. Dagegen handelt es sich bei der Reinigung von Gebäuden teilweise um Holzoberflächen und historische Bauten, deren Oberfläche besonders schonend gereinigt werden muss, auch um eine schnelle Neuverschmutzung zu vermeiden. Bei der Reinigung von Brauerei- und Winzer-Produktionsanlagen sowie in der Lebensmittelindustrie darf zusätzlich nicht mit Chemie gereinigt werden, um die Qualität der Produkte nicht zu gefährden.

\section{Schnell zum gewünschten Ergebnis}

Unabhängig davon, ob größere Flächen, filigrane Elemente oder geometrisch komplexe Oberflächen $\mathrm{zu}$ reinigen sind, die verschiedenen Geräten ermöglichen eine optimale angepasste Reinigung, bei der das gewünschte Ergebnis erzielt wird. Einen Beitrag dazu leistet auch das Sortiment an Strahldüsen, beispielsweise die Fragmentier-Mern-Düse, in der die einzelnen Pellets in mehrere Teile zerkleinert werden. //

\section{Kontakte}

Cold Jet Deutschland GmbH

Weinsheim, Tel. 06551 9606-0

www.coldjet.com 